\title{
Standing tree assessment for the maintenance of historic wooden buildings: a case study of a World Heritage site in China
}

\author{
Weida Yin, Hirokazu Yamamoto
}

Historic wooden buildings are a symbol of China's "culture of wood" and require extraction of forest resources for their renovation. In the $21^{\text {st }}$ century, natural resources are limited globally, and sustainable solutions are needed. In this study, we established a new method to connect building and forest sites for efficient utilization of limited forest resources for the renovation of historic buildings. We obtained measurements of large wooden components from Shenyang Imperial Palace. We also performed morphometric analyses on 47 thinned, old-growth larch trees to determine the relative taper curve, and selected 108 standing trees for simulation of the tree-height curve in the Mt. Changbai area, Jinlin Province, Northeast China. On the basis of forest metrology, we established an upper tree prediction method. By measuring the diameter at breast height (DBH) alone, we could compare size information (e.g., diameter, length) for standing trees and wooden building components. This method was then applied to estimate the required DBH class of standing trees for the renovation of Shenyang Imperial Palace.

Keywords: Sustainable Renovation, Relative Taper Curve, Tree Height Curve, Standing Tree Assessment, Historic Wooden Buildings

\section{Introduction}

Environmental protection has become one of the most urgent contemporary issues. Understanding the relationship between humans and nature requires that the wooden heritage buildings, a global concern, be considered the most important wealth for individuals who constantly reflect on their roles in nature (Yamamoto 2010). Intact historic wooden buildings are evidence of the wisdom and craftsmanship of ancient people and are of practical significance for exploring the sustainable use and restoration of renewable forest resources.

As of 2010, 29 world cultural heritage sites have been approved in China, including 14 timber-frame buildings. China includes 1080 historic building complexes that are listed as protected sites, more than half of which are timber-frame buildings. The International Council on Monuments and Sites (ICOMOS) under the auspices of the United $\mathrm{Na}$ tions Educational, Scientific and Cultural

Organization (UNESCO) established the "principles for the preservation of historic timber structures" that include the preservation of the "same tree species", "tree quality" and "building techniques" (Yin et al. 2012). Therefore, the maintenance of traditional Chinese wooden buildings requires that specific types and quantities of high-quality wood be available in the timber market.

Recently, there has been a precipitous decrease in the production of large-diameter, high-quality wood due to social and economic changes. In 1998, the Chinese government implemented the Natural Forest Conservation Projects (NFCP) policy in an effort to promote forest management activities that prevent further deterioration of these resources (Chen 2004). This policy, which emphasizes the protection of existing natural forests from excessive cutting, has been implemented in 18 provinces and several autonomous regions (Li 2004). Although this policy has facilitated ecological preservation,

Graduate School of Frontier Science, the University of Tokyo, 5-1-5 Kashiwanoha, Kashiwa, 277-8563 Chiba (Japan)

(a) Weida Yin (maximusinjapan@gmail.com)

Received: Aug 29, 2012 - Accepted: Mar 07, 2013

Citation: Yin W, Yamamoto H, 2013. Standing tree assessment for the maintenance of historic wooden buildings: a case study of a World Heritage site in China. iForest 6: 169-174 [online 2013-05-08] URL: http://www.sisef.it/iforest/contents/?id=ifor0753-006

Communicated by: Marco Borghetti it has affected domestic timber production. The challenge of promoting conservation while seeking to acquire large volumes of wood from natural forests for historic renovation is not unique to China but is also experienced in countries such as Japan and Sweden (Osawa et al. 2004).

Efficient utilization of natural forest resources is the key issue in renovating historic wooden buildings, and the amount of wood required from standing trees needs to be accurately assessed. Methods for estimating the upper stem diameter have been used by many researchers (Kozak \& Smith 1993 , Gaffrey et al. 1998, Sato et al. 2008, Brooks et al. 2012) and can be considered as a tool for improving the economic utilization of timber.

The objective of this research was to develop a method for the identification of standing tree branches using the forest measurement techniques to obtain the large wood components required for the renovation of the Shenyang Imperial Palace. By using this method and the data acquired from the measurements of the building sites, we could predict the required standing tree size for the renovation of the Shenyang Imperial Palace. Such prediction will facilitate compatibility between building conservation and forest management and help promote sustainable management of historic wooden buildings in China.

\section{Materials and methods}

Two steps were taken to ensure consistency between the types of wooden structures that comprised the Shenyang Imperial Palace and the tree species present in the Mt. Changbai forest site: (1) measurement of wood structures and data collection from Shenyang Imperial Palace (building site); and (2) field work in the natural forest in the Mt. Changbai area (forest site).

\section{Building Site}

The Shenyang Imperial Palace is located in northeast China. Built in 1624-1625 (Qing Dynasty), the palace was catalogued as the $28^{\text {th }}$ cultural heritage site of the UNESCO World Heritage Committee's Ming and Qing Imperial Palace expansion projects, comparable to the Forbidden City in Beijing. The total land area occupied by the palace is approximately $0.6 \mathrm{~km}^{2}$ and includes 67 buildings (Piao \& Chen 2010).

Three-dimensional information (length, width, height) of wooden components was measured to determine the size of timbers that would be necessary for the renovation of Shenyang Imperial Palace. According to different architectural types, 28 representative buildings, including 4 major categories (column, beam, purlin, and tie-beam) were selected in this research. The remaining 
buildings having the same architectural features and forms of the 28 representative buildings were not measured.

Morphometric measurements of each large wooden component were obtained on the basis of the following sources (Yin et al. 2012):

- The building plans, including the floor plan, building-section plan, and cross-section plan (scale: 1:30, 1:40, and 1:50, respectively), drawn by Tianjin University.

- On-site measurement of the bottom diameter of the eave column of each of the 28 buildings in the palace complex to verify the accuracy of the data measured on the plan (Yin et al. 2012). The statistical test of accuracy was derived using the method proposed by Wang et al. (2006).

Assuming that each large wooden building component was constructed using a single raw wooden column, and that the cross-sections of some wood components were square or polygonal, the maximum diagonal crosssection was calculated for each wooden component to estimate the diameter of the raw timber required.

\section{Forest Site}

\section{Tree species}

Old-growth larch (Larix olgensis) forests are primarily distributed in northeast China in Jilin Province. Excessive logging in recent decades has led to the gradual reduction and eventually uneven distribution of natural larch forest. In this study, L. olgensis was selected as experimental tree species for two reasons: (1) it was used for many of the large wooden components found in imperial palaces (Jin \& Huang 2007); and (2) it is the main species of several rare natural forest reserves.

\section{Study site description and sampling}

As per the UNESCO guidelines, sites at Huang Songpu Forest Farm in the Baihe Forest District of Jilin Province (lat $42^{\circ} 08^{\prime} 21^{\prime \prime} \mathrm{N}$, long. $\left.128^{\circ} 16^{\prime} 53^{\prime \prime} \mathrm{E}\right)$ were selected for allometric measurement. These sites are located $10 \mathrm{~km}$ north of the Mt. Changbai Biosphere Reserve area (Yang \& Xu 2003) and have a mean annual temperature of 5.0 ${ }^{\circ} \mathrm{C}$. The lowest and highest monthly mean temperatures are $-17.1{ }^{\circ} \mathrm{C}$ in January and $17.1{ }^{\circ} \mathrm{C}$ in July, respectively; mean annual precipitation is $719 \mathrm{~mm}$ (Zhou et al. 2006).

Two adjacent sub-compartments with a total area of 6.57 ha were selected due to the first thinning activities conducted by Huang Songpu Forest Farm. Both the sub-compartments were representatives of natural, oldgrowth, multi-storied coniferous forest in northeast China. These forested areas are dominated by Changbai larch (L. olgensis Henry), followed by spruce (Picea jezoensis var. microsperma), Korean pine (Pinus ko- raiensis Sieb. et Zucc.), and fir (Abies nephrolepis, Trautv, Maxim).

Forty-seven trees were felled, and the total height of each was measured to the nearest $0.03 \mathrm{~m}$. Diameter outside bark (DOB) was measured at breast height (DBH, $1.3 \mathrm{~m})$. DOB was also measured at intervals of $2 \mathrm{~m}$ along the length of the stem, beginning at $0.3 \mathrm{~m}$. The DOB at $1 / 10$ tree height was recorded to create a relative taper curve. The maximum tree height $(34.7 \mathrm{~m})$, maximum DBH $(67.8 \mathrm{~cm})$, and maximum diameter at $1 / 10$ tree height $(58.2 \mathrm{~cm})$ of the 47 trees sampled were recorded. In addition to the 47 thinned trees, the DBH and height of 61 standing trees in the same field area were measured. In total, 108 standing old-growth larch trees were measured to calculate the tree height curve.

Establishing the size exchange method for building components and standing trees based on tree height curve and relative taper curve

The relationship between tree height and DBH is considered to define the tree height curve (H-D). The Henricksen equation was applied to simulate the tree height curve (eqn. 1):

$$
H=a+b \cdot \log D
$$

where $H$ is the tree height, $D$ is the $\mathrm{DBH}$, and $a$ and $b$ are model parameters to be estimated.

The tree-height curve of $L$. olgensis in plantation forests has been estimated by several researchers; however, the majority of plantation trees were $<50$ years old (Zeng et al. 2009, Ma et al. 2010). To our knowledge, there is no literature reporting on the treeheight curve of old-growth larch in natural forests of Mt. Changbai. Thus, we calculated the curve based on the 108 samples from our study area.

Relative taper curve is the mathematical expression of the change in stem diameter as a function of stem height, which is calculated on the basis of tree conditions (Jiang \& Liu 2011 - eqn. 2):

$$
D_{r}=D \cdot D_{0.1 \mathrm{~h}}^{-1}
$$

where $D_{\mathrm{r}}$ is the relative diameter, $D$ is the diameter at a specified height, and $D_{0.1 \mathrm{~h}}$ is the diameter at 1/10 tree height; and (eqn. 3):

$$
H_{r}=1-H \cdot H_{t}^{-1}
$$

where $H_{\mathrm{r}}$ is the relative tree height, $H$ is the tree height at a specified point, and $H_{\mathrm{t}}$ is the total tree height.

Measured field data (e.g., diameter at different heights) were converted into relative height and relative diameter to generate the model. Sato and co-workers (2008) utilized a third-order equation to create a relative taper curve across an entire range of tree-height data. However, the portions of standing trees that can be utilized as timber for historic renovation occur within specific height intervals. Therefore, a third-order equation would reduce the accuracy of the results for our purposes. In this research, third-, fourth-, fifth-, and sixth-order formulae were applied separately for comparing the accuracy for specific tree-height intervals (eqn. 4 , eqn. 5 , eqn. 6 , eqn. 7 ):

$$
\begin{gathered}
D_{r}=a H_{r}^{3}-b H_{r}^{2}+c H_{r} \\
D_{r}=e H_{r}^{4}-f H_{r}^{3}+g H_{r}^{2}+i H_{r} \\
D_{r}=j H_{r}^{5}-k H_{r}^{4}+l H_{r}^{3}-m H_{r}^{2}+n H_{r} \\
D_{r}=o H_{r}^{6}-p H_{r}^{5}+q H_{r}^{4}-r H_{r}^{3}+s H_{r}^{2}+t H_{r}
\end{gathered}
$$

where $D_{\mathrm{r}}$ is the relative diameter, $H$ is the relative height, and $a$ to $t$ are model coefficients to be estimated.

Assuming that wooden tree parts are cylindrical, the length of a trunk can be considered to be equal to the height from the ground, and the diameter can be considered to be equal along the length of the tree. Tree mensuration data were converted into $2 \mathrm{va}$ riables of a standing tree. The variables DBH, $H_{\mathrm{i}}$ (any height above ground) and $D_{\mathrm{i}}$ (upper diameter at $H_{\mathrm{i}}$ ) could be used to estimate $D_{\mathrm{i}}$ on the basis of the other 2 variables. Following eqn. 1-7, the derivation process was as follows:

- DBH and eqn. 1 were used to deduce the total tree height.

- Total tree height and eqn. 3 were used to deduce the relative tree height at $1.3 \mathrm{~m}$.

- The relative tree height at $1.3 \mathrm{~m}$ and eqn. 4 , eqn. 5 , eqn. 6 , or eqn. 7 were used to deduce the relative diameter at $1.3 \mathrm{~m}$.

- DBH and relative diameter at breast height were used to deduce $D_{0.1 \mathrm{~h}}$.

- $H_{\mathrm{i}}$, total tree height, and eqn. 3 were used to deduce the relative tree height at that $H_{\mathrm{i}}$.

- Relative tree height at $H_{\mathrm{i}}$ and eqn. 4, eqn. 5 , eqn. 6 , or eqn. 7 were used to deduce the relative diameter at $H_{\mathrm{i}}$.

- Known $D_{0.1 \mathrm{~h}}$, relative diameter at $H_{\mathrm{i}}$, and eqn. 2 were used to deduce $D_{\mathrm{i}}$.

\section{Estimating the sapwood with bark value of standing trees}

The information on wooden components from the building site and trees from the forest site were well connected; however, for renovation purposes, sapwood with bark could not be included as their physical and chemical properties are not suitable for construction. Therefore, the values of sapwood and bark were recorded together. For each sample, two perpendicular lines intersecting at the centre were measured in order to derive four sapwood with bark values; corres- 
Tab. 1 - Number of large-sized wooden components from Shenyang Imperial Palace.

\begin{tabular}{|c|c|c|c|c|c|c|c|c|c|c|c|}
\hline \multirow{2}{*}{$\begin{array}{c}\text { Diameter } \\
\text { class } \\
\text { (cm) }\end{array}$} & \multicolumn{10}{|c|}{ Length (m) } & \multirow{2}{*}{ Total } \\
\hline & 4-5 & $5-6$ & $6-7$ & $7-8$ & 8-9 & $9-10$ & $10-11$ & $11-12$ & $12-13$ & $13-14$ & \\
\hline $50-52$ & 12 & - & 4 & 10 & - & 8 & - & - & - & - & 34 \\
\hline $52-54$ & 32 & 8 & - & 2 & - & - & - & - & - & - & 42 \\
\hline $54-56$ & 20 & - & 8 & 4 & - & - & - & - & - & - & 32 \\
\hline $56-58$ & - & 6 & 4 & - & - & - & - & - & - & 12 & 22 \\
\hline $58-60$ & - & 12 & 32 & - & - & - & - & - & - & - & 44 \\
\hline $60-62$ & - & - & - & - & - & - & - & - & - & - & 0 \\
\hline $62-64$ & - & - & 12 & 14 & - & - & - & - & - & - & 26 \\
\hline $64-66$ & - & 16 & - & - & - & - & - & - & - & - & 16 \\
\hline $66-68$ & 6 & - & - & - & - & - & - & - & - & - & 6 \\
\hline $68-70$ & - & - & - & 26 & - & - & - & - & - & - & 26 \\
\hline $70-72$ & - & 6 & - & - & - & - & 12 & - & - & - & 18 \\
\hline $72-74$ & - & - & - & 8 & 6 & - & 2 & - & - & - & 16 \\
\hline $74-76$ & - & - & 6 & 12 & - & 16 & - & - & - & - & 34 \\
\hline $76-78$ & - & - & 8 & - & - & - & - & - & - & - & 8 \\
\hline $78-80$ & - & - & - & - & - & - & 18 & - & - & 6 & 24 \\
\hline $80-82$ & - & - & - & - & 18 & - & - & - & - & - & 18 \\
\hline $82-84$ & - & - & - & - & - & - & - & - & - & - & 0 \\
\hline $84-86$ & - & - & - & - & - & 2 & - & - & - & - & 2 \\
\hline Total & 70 & 48 & 74 & 76 & 24 & 26 & 32 & 0 & 0 & 18 & 368 \\
\hline
\end{tabular}

ponding stem diameter values were also recorded. In all, 52 sets of paired data were measured.

\section{Model evaluation}

The criteria for model evaluation in this research followed recommendations by Kozak $\&$ Smith (1993). The statistics used for comparing the models were average bias $(B)$, standard error of the estimate $(S E)$, and a fit index $(F I)$. These evaluation statistics were expressed as (eqn. 8, eqn. 9 , eqn. 10):

$$
\begin{array}{r}
B=\frac{\sum_{i=1}^{n}\left(Y_{i}-\hat{Y}_{i}\right)}{n} \\
S E E=\sqrt{\frac{\sum_{i=1}^{n}\left(Y_{i}-\hat{Y}_{i}\right)^{2}}{n-k}} \\
F I=1-\left[\frac{\sum_{i=1}^{n}\left(Y_{i}-\hat{Y}_{i}\right)^{2}}{\sum_{i=1}^{n}\left(Y_{i}-\bar{Y}_{i}\right)^{2}}\right]
\end{array}
$$

where $Y_{\mathrm{i}}$ is value for the $i$-th observation, $\hat{Y}_{1}$ is the predicted value for the $i$-th observation, $\bar{Y}$ is the mean of $Y_{\mathrm{i}}$ values, $k$ is the number of estimated parameters, and $n$ is the number of observations in the dataset.

\section{Results}

Size of wooden building components

Statistical results (Yin et al. 2012) showed that direct measurements of eave columns and data derived from building plans coincide well $\left(\mathrm{R}^{2}=0.94, p<0.01\right)$, suggesting that the use of building plans to measure eave columns and other components is accurate.

The basic criteria for the selection of large wooden components used for the statistical analyses in this study were length $\geq 4 \mathrm{~m}$ and diameter $\geq 50 \mathrm{~cm}$. A total of 368 large wooden components were calculated from the study materials, and these data were segregated and tallied by length and diameter in 1-m and 2-cm intervals, respectively (Tab. 1). There was no significant bias between the diameter of the bottom and top of each wooden component; thus the diameter reported in Tab. 1 is the bottom diameter value. The building site data revealed the longest wooden component to be a hypostyle column with length of $13.7 \mathrm{~m}$. Tab. 1 shows that large wooden components ranged in size from 4 to $14 \mathrm{~m}$ long and from 50 to $86 \mathrm{~cm}$ in diameter.

\section{Measurement of sapwood with bark} value

The relationship between stem diameter value and sapwood with bark value is shown in Fig. 1. The Kolmogorov-Smirnov test showed that the stem diameter value was significantly correlated with the sapwood with bark value ( $p=0.001$, correlation is significant at the 0.01 level). The correlation coefficient between stem diameter and the sapwood with bark value is 0.46 . The linear regression model was calculated as (eqn. 11):

$$
Y=0.0226 \cdot X+1.2428
$$

where $Y$ is the sapwood with bark value (one side) and $X$ is stem diameter.

\section{Tree height curve}

The range of sample DBH values varied from 23.6 to $67.8 \mathrm{~cm}$, and tree height ranged from 21.7 to $36.8 \mathrm{~m}$ (Fig. 2). The relationship between DBH and tree height is evident from eqn. 12:

$$
Y=12.356 \ln (X)-15.655
$$

where $Y$ is tree height and $X$ is $\mathrm{DBH}$.

\section{Relative taper curve}

The third- through sixth-order equations were expressed as (eqn. $13-3^{\text {rd }}$ order, eqn. $14-4^{\text {th }}$ order, eqn. $15-5^{\text {th }}$ order, eqn. $16-6^{\text {th }}$ order, respectively):

$$
\begin{aligned}
y= & 2.4296 \mathrm{x}^{3}-3.577 \mathrm{x}^{2}+2.3624 \mathrm{x} \\
y= & 5.9659 \mathrm{x}^{4}-9.096 \mathrm{x}^{3} \\
+ & 3.2037 \mathrm{x}^{2}+1.1994 \mathrm{x} \\
y= & 17.362 \mathrm{x}^{5}-36.669 \mathrm{x}^{4}+27.24 \mathrm{x}^{3} \\
& -9.1812 \mathrm{x}^{2}+2.5562 \mathrm{x} \\
y= & 45.75 \mathrm{x}^{6}-118.52 \mathrm{x}^{5}+114.26 \mathrm{x}^{4} \\
& -49.608 \mathrm{x}^{3}+8.2154 \mathrm{x}^{2}+1.2259 \mathrm{x}
\end{aligned}
$$

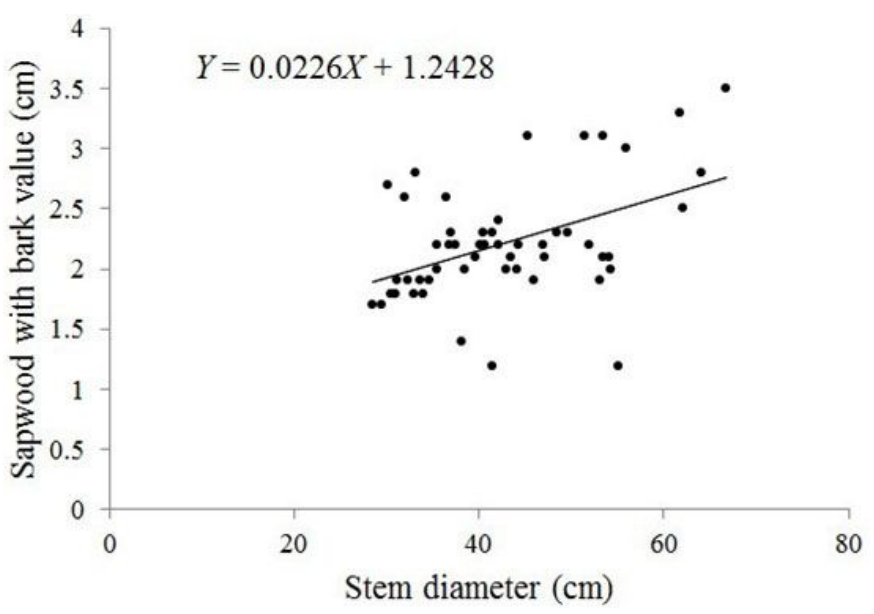

Fig. 1 - Relationship between stem diameter and sapwood with bark value. 


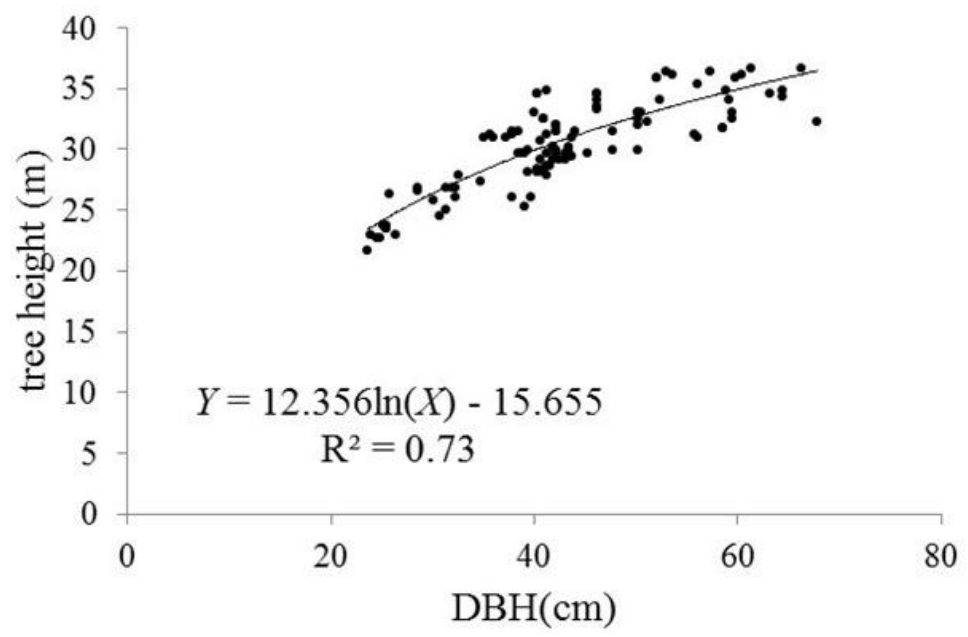

Fig. 2 - Tree height curve.

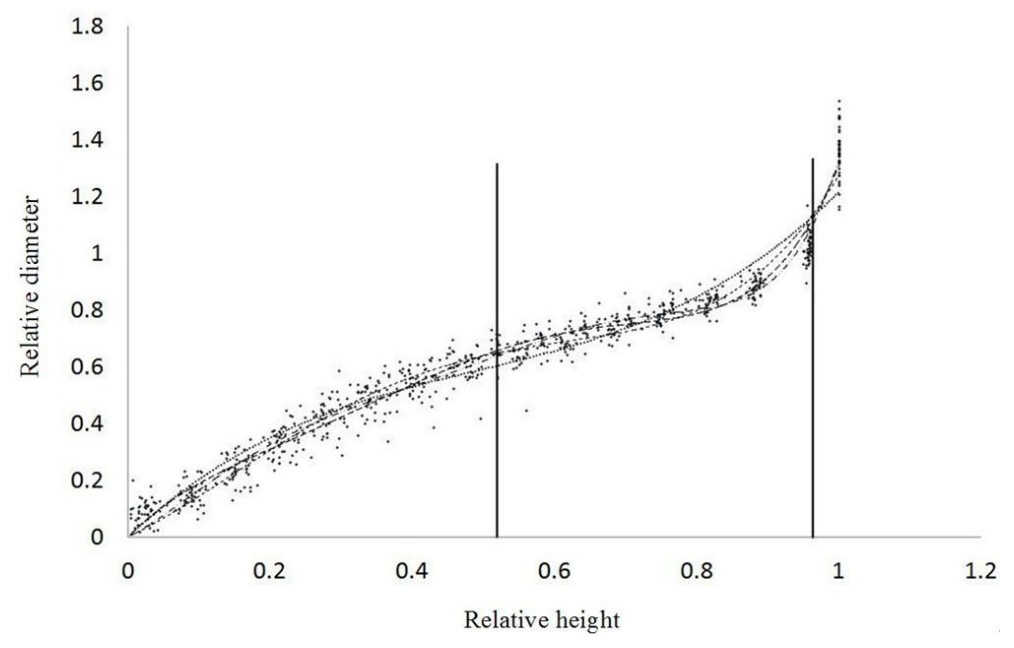

Fig. 3 - Comparison of different relative taper curves.

Segmented polynomial models appear to be more accurate than other model formulations for estimating tree diameter (Jiang et al. 2005). We compared eqn. 13 to 16 within a certain range for improving the overall statistical accuracy (Tab. 2). The longest

wooden components from Shenyang Imperial Palace were up to $13.7 \mathrm{~m}$. The portion of forest trees up to $1 \mathrm{~m}$ aboveground was not considered as useful timber material because of the trunk shape. Therefore, the useful range for supporting renovation of the his-

Tab. 3 - Upper diameter prediction for a given tree height.

\begin{tabular}{|c|c|c|c|c|c|c|c|}
\hline \multirow{2}{*}{$\begin{array}{c}\text { DBH } \\
(\mathrm{cm})\end{array}$} & \multicolumn{7}{|c|}{ Upper tree diameter prediction (m) } \\
\hline & $h=\mathbf{3}$ & $h=4$ & $h=5$ & $h=6$ & $\ldots$ & $h=19$ & $h=\mathbf{2 0}$ \\
\hline 40 & 33.4 & 31.6 & 30.6 & 30 & $\cdots$ & 18.8 & 17.6 \\
\hline 42 & 35.1 & 33.2 & 32.1 & 31.4 & $\ldots$ & 20.1 & 18.9 \\
\hline 44 & 36.8 & 34.7 & 33.5 & 32.9 & $\ldots$ & 21.4 & 20.2 \\
\hline 46 & 38.5 & 36.3 & 35 & 34.3 & $\ldots$ & 22.7 & 21.5 \\
\hline 48 & 40.2 & 37.9 & 36.5 & 35.8 & $\ldots$ & 24 & 22.7 \\
\hline 50 & 41.9 & 39.5 & 38 & 37.2 & $\cdots$ & 25.3 & 24 \\
\hline$\ldots$ & $\ldots$ & $\ldots$ & $\ldots$ & $\ldots$ & $\ldots$ & $\ldots$ & $\ldots$ \\
\hline 70 & 59.1 & 55.5 & 53.2 & 51.8 & $\ldots$ & 38.4 & 36.8 \\
\hline 80 & 67.8 & 63.6 & 60.8 & 59.1 & $\ldots$ & 45 & 43.3 \\
\hline 90 & 76.5 & 71.7 & 68.5 & 66.5 & $\ldots$ & 51.7 & 49.9 \\
\hline 100 & 85.2 & 79.8 & 76.2 & 73.8 & $\ldots$ & 58.4 & 56.4 \\
\hline
\end{tabular}

Tab. 2 - Segmented stem-fit statistics of for relative taper curve simulations.

\begin{tabular}{llll}
\hline Equation & \multicolumn{1}{c}{ B } & SEE & \multicolumn{1}{c}{ FI } \\
\hline Third-order & -0.019 & 0.0694 & 0.8271 \\
Fourth-order & -0.0071 & 0.0602 & 0.8441 \\
Fifth-order & -0.0081 & 0.0531 & 0.8411 \\
Sixth-order & -0.0046 & 0.0465 & 0.858 \\
\hline
\end{tabular}

toric palace was considered to be located between 1-14.7 $\mathrm{m}$ above ground. The average value of 47 samples used to generate the taper curve was $30.55 \mathrm{~m}$ in height; therefore, the segmented polynomial range was set on the scale between 0.52 and 0.97 (relative height - Fig. 3).

Overall statistics of fit ( $B, S E E$, and $F I)$ for the four segmented polynomial equations are presented in Tab. 2. The $B$ value was negative for all equations, indicating that the predicted diameter was greater than the actual diameter. Size information derived from the model will thus be larger than the actual diameter in case the predicted value cannot satisfy the size of replacement wooden parts from the building site. The $F I$ value indicates a trend of increasing fit with increasing equation order. When the estimated $S E E$ values from eqn. 13 to eqn. 16 are transformed into actual diameter, the values are 2.87, $2.49,2.19$, and $1.93 \mathrm{~cm}$, respectively. In this study, an acceptable error range for diameter is $2 \mathrm{~cm}$, equal to the unit of measurement in the wood market. Therefore, the sixth-order equation was chosen for simulating the relative taper curve in this study.

The diameter of a tree's upper section could be considered as a desirable size for wooden building components, because the upper diameter is considered to produce the maximum timber size. The derivation process presented in the methods (using eqn. 13 for relative taper curve) can be used to determine the diameter of a standing tree's upper section by using the single measurement of DBH (Tab. 3). Furthermore, the estimation data must incorporate the two-sided value of sapwood with bark (calculated using eqn. 11). Finally, the suitability of standing trees for use in wooden components can be matched with the requirements of the building sites.

For example, when the DBH of a standing tree is $50 \mathrm{~cm}$ (Tab. 3), the upper tree diameter at a tree height of $5 \mathrm{~m}$ is $38 \mathrm{~cm}$. By applying eqn. 11, the two-sided sapwood with bark value at a tree height of $5 \mathrm{~m}$ can be calculated as $(2.1 \mathrm{~cm} \times 2=4.2 \mathrm{~cm})$. Therefore, the maximum available diameter at a tree height of $5 \mathrm{~m}$ is: $38 \mathrm{~cm}-4.2 \mathrm{~cm}=33.8 \mathrm{~cm}$. Furthermore, the lowest $1 \mathrm{~m}$ from ground of the trunk cannot be used as wooden parts for buildings since it has an irregular shape. In conclusion, standing trees that can produce timber having a diameter of $33.8 \mathrm{~cm}$ and a 


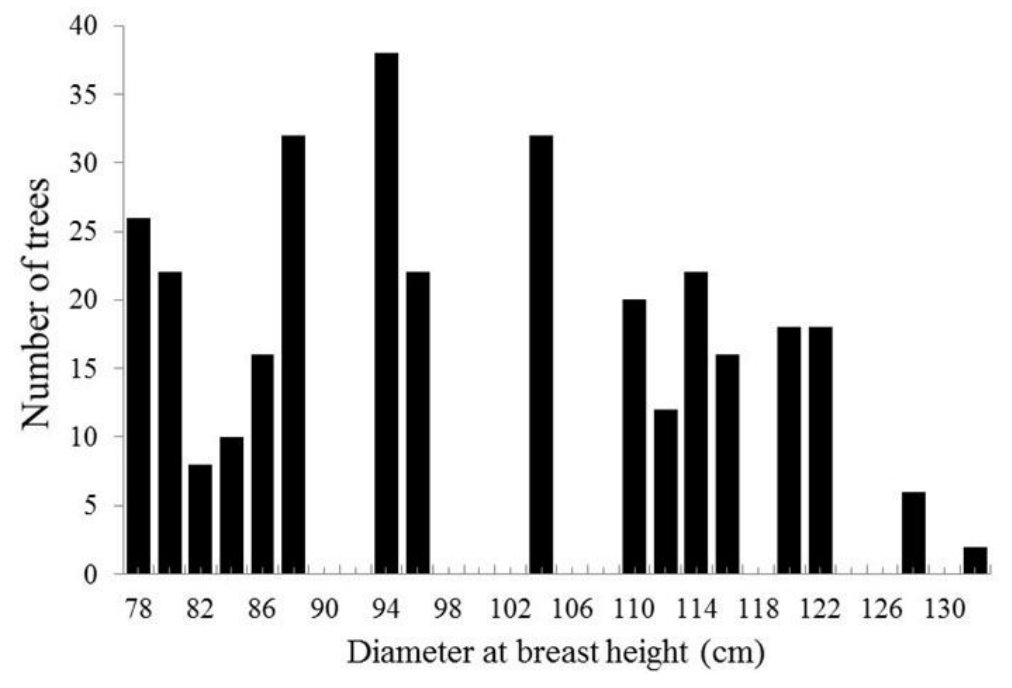

Fig. 4 - Number of Larix trees by diameter class required to support the renovation of Shenyang Imperial Palace.

length of $4 \mathrm{~m}$ will have a minimum $\mathrm{DBH}$ of $50 \mathrm{~cm}$. According to this method, the wooden parts' information obtained from building sites is well associated with the $\mathrm{DBH}$ information obtained from the forest sites.

By using the information presented in Tab. 3 and the data on the requirements of the building site (Tab. 1), one can estimate the standing tree size requirements. Fig. 4 shows the number of Larix DBH size-classes required to support renovation of the Shenyang Imperial Palace.

\section{Discussion}

Application of samples from forest sites

Tree samples collected from the forest had some limitations. For example, the largest tree had a length of $34.7 \mathrm{~m}$ and DBH of 67.8 $\mathrm{cm}$. Thus, the diameter class under $67.8 \mathrm{~cm}$ can be estimated accurately, but estimation of larger trees may be of limited accuracy. We separated 47 tree samples into 2 groups based on $D_{0.1 \mathrm{~h}}$. Six samples were $>45 \mathrm{~cm}$ at $D_{0.1 \mathrm{~h}}$ (maximum $D_{0.1 \mathrm{~h}}$ was $58.2 \mathrm{~cm}$ ). For the remaining 41 samples, the maximum $D_{0.1 \mathrm{~h}}$ was $44.6 \mathrm{~cm}$. The $S E E$ values of these 2 groups, simulated using sixth-order equations, were 0.01 and 0.04 , respectively. Transferring the difference into real diameter $(44.6 \mathrm{~cm} \times 0.04-58.2 \mathrm{~cm} \times 0.01)$, a value of $1.2 \mathrm{~cm}$ was obtained. Therefore, the size of the sample trees would not significantly affect the relative taper curve, and the method of estimating upper tree diameter can also be applied to larger samples. The method confirmed that the relative taper curve can be stabilized by dividing existing samples into 2 groups; nevertheless, there is still uncertainty for predicting the taper curve for some samples that have larger diameter beyond the sample's size. The predicted values in Tab. 3 (e.g., $\mathrm{DBH}>70 \mathrm{~cm}$ ) were obtained by extrapolating from the taper curve; accordingly, the results may be inaccurate. Therefore, future research should test the accuracy of the created relative taper curve.

Rethinking the outline of ICOMOS and the possibility of shifting NFCP policy

According to our experimental results, availability of large-size timber material in China is unlikely to be sufficient to meet the requirements of historic renovation. This problem is not exclusive to China; it is relevant in other countries where wooden buildings play an important historical role. In Japan, obtaining good-quality wood from natural forests is a serious problem. Former conservators used alternative tree species that could be obtained easily when the preferred tree was not available (Osawa et al. 2004). In Norway, the Wood Bank Project was implemented in 1992 to supply lumber for the renovation of 300 middle-age wood buildings.

Our results (Fig. 4) suggest that the estimated required DBH value of standing trees ranges from 78 to $136 \mathrm{~cm}$ for the renovation of the Shenyang Imperial Palace. This range of DBH represents extremely high-quality forest resources, which we did not find based on our experimental forest work. The ICOMOS ideals are summarized with the phrase: "Same tree species, tree quality and building technique". These ideals will be difficult to realize for the reasons discussed in this paper. Efforts should be made regarding both building and forest sites. In the case of building sites, it should be a priority to compile details on the volume of wooden components that comprise each site. With regard to forest sites, an alternative system of tree production should be devised to enable maintenance of renovation cycles for historic wooden buildings. Because the wood supply cannot be derived from natural forest resources alone, an effective combination that utilizes plantation and natural forest resources will be necessary.

\section{Conclusions}

This research developed an efficient method for identifying upper tree diameter based on natural forests in the Mt. Changbai area, northeast China. By applying this method, we transferred the information on wooden components from a historic building site into DBH information on standing trees and estimated available standing tree resources for the renovation of the Shenyang Imperial Palace. Nevertheless, further attempts to bridge the sometimes-contrasting interests of building renovation and forest management are required.

\section{Acknowledgments}

This study was funded by a Grant-in-Aid for Scientific Research, Scientific ResearchA, No. 20240074 (2008-2010) and No. 23240113 (2011-2013) from the Japan Society for the Promotion of Science. We would like to thank Sun Chen, Marcin, and Yang Jian for their efforts on this paper; Sato Juri and Assist. Prof. Terada for their kind advices; and Prof. Yin Mingfang and their collegues for support in the field work.

\section{References}

Brooks JR, Jiang L, Ozcelik R (2012). Compatible stem volume and taper equations for Brutian pine, Cedar of Lebanon, and Cilicica fir in Turkey. Forest Ecology and Management 256 (1-2): 147-151. - doi: 10.1016/j.foreco.2008.04.018 Chen P (2004). Natural forest protection: an overview abroad and a review at home. Journal of Beijing Forestry University Social Sciences 3 (2): 50-54. [In Chinese with English abstract] Gaffrey D, Sloboda B, Matsumura N (1998). Representation of tree stem taper curves and their dynamic, using a linear model and the centroaffine transformation. Journal of Forest Research 3 (2): 67-74. - doi: 10.1007/BF027 60304

Jiang L, Brooks JR, Wang J (2005). Compatible taper and volume equations for yellow-poplar in West Virginia. Forest Ecology and Management 213: 399-409. - doi: 10.1016/j.foreco.2005.04. 006

Jiang L, Liu R (2011). Segmented taper equations with crown ratio and stand density for Dahurian larch (Larix gmelinii) in Northeast China. Journal of Forest Research 22 (3): 347-352. - doi: 10.1007/s11676-011-0178-4

Jin H, Huang R (2007). A study of the types of timber used in the hall of martial valour (wuying dian) group of buildings and matching them. Palace Museum Journal 132 (3): 6-27.

Kozak A, Smith JHG (1993). Standards for eva- 
luating taper estimating systems. The Forest Chronicle 69: 438-444.

Li W (2004). Degradation and renovation of forest ecosystems in China. Forest Ecology and Management 201: 33-41. - doi: 10.1016/j.foreco. 2004.06.010

Ma X, Zhong Z, Sun Z (2010). Compilation on volume table of Larix olgensis plantation in hilly area of Sanjiang Plain. Forest Engineering 26 (5): 1-3.

Osawa Y, Goto O, Trifkovic S, Yamamoto $\mathrm{H}$ (2004). Forest resources management for the renovation of wooden cultural buildings in Japan-Horyuji temple in Nara Prefecture. In: FORCOM Abstract Proceedings of the "International Symposium on The Role of Forests for Coming Generations", pp. 92-95.

Piao Y, Chen BC (2010). Research on timber construction in the imperial palace of the Qing Dy- nasty in Shenyang ( $1^{\text {st }}$ edn.). Southeast University Press, Nanjing, China. [in Chinese]

Sato J, Yamamoto H, Tatsumi T (2008). Study on evaluating a standing tree used for wooden cultural buildings-about the method to presume size and quality of the timber. Forest Resources and Mathematical Modeling 8:1-12. [in Japanese with English abstract]

Wang X, Fang J, Tang Z, Zhu B (2006). Climatic control of primary forest structure and $\mathrm{DBH}-$ height allometry in Northeast China. Forest Ecology and Management 234: 264-274. - doi: 10.1016/j.foreco.2006.07.007

Yamamoto H (2010). Forest resources management to support the Japan's "Culture of Wood." Journal of Forest Planning 16: 99-105.

Yang X, Xu M (2003). Biodiversity conservation in Changbai Mountain Biosphere Reserve, northeastern China: status, problem, and strategy.
Biodiversity and Conservation 12: 883-903. doi: 10.1023/A:1022841107685

Yin WD, Yamamoto H, Yin MF, Gao J, Stanko T (2012). Estimating the volume of large-size wood parts in historical timber-frame buildings of China: case study of Imperial Palaces of the Qing Dynasty in Shenyang. Journal of Asian Architecture and Building Engineering 11: 321326. - doi: 10.3130/jaabe.11.321

Zeng C, Lei XD, Liu X, Zhao L, Yang Y (2009). Individual tree height-diameter curves of larchspruce-fir forests. Forest Research 220: 182-189. [In Chinese with English abstract]

Zhou L, Dai LM, Guo FS, Xu D, Wang H, Bai JW (2006). GIS-based analysis of forest degradations in Baihe Forestry Bureau, northeast China. Science in China, Series E Technological Sciences 49: 167-176. - doi: 10.1007/s11431-006-8118-9 